\title{
Ecological associations between asthma prevalence and potential exposure to farming
}

\author{
L. Elliott*, K. Yeatts*, D. Loomis*,\#
}

Ecological associations between asthma prevalence and potential exposure to farming. L. Elliott, K. Yeatts, D. Loomis. C) ERS Journals Ltd 2004.

ABSTRACT: Farming and exposure to livestock have been proposed as protective against the development of asthma in children. An ecological study was conducted to examine the support for these relationships in the USA.

County-specific aggregate measures were used to examine the relationship between the prevalence of asthma and wheeze in 7 th and 8th grade school children (aged 12-14 yrs) and selected measures of potential exposure to farming in the state of North Carolina. Binomial regression models were fitted to quantify these relationships, with adjustments for parental smoking, socioeconomic status, sex and race. Regression coefficients were reported for an increment of one interquartile range (IQR) in each indicator of exposure.

The prevalence of asthma showed decreasing trends for most indicators of farm exposure. Regression results suggested that the largest decreases in asthma prevalence were associated with the number of farms $(-5.0 \%$ per IQR increment), acreage of hay (-7.2\% per IQR increment) and beef cattle (-7.8\% per IQR increment). The pattern of results was similar for wheezing.

In conclusion, the findings of this study are consistent with the hypothesis that certain farm exposures are protective against childhood asthma. Further research with individual-level data is needed to identify the specific protective exposures.

Eur Respir J 2004; 24: 938-941.
Depts of *Epidemiology and ${ }^{\#}$ Environmental Sciences, University of North Carolina, Chapel Hill, NC, USA.

Correspondence: L. Elliott

National Institute of Environmental Health Sciences

MD A2-05

P.O. Box 12233

RTP

NC 27709

USA

Fax: 19199676839

E-mail: elliott1@niehs.nih.gov

Keywords: Agriculture

asthma

childhood disease

ecological study

farming

livestock

Received: January 182004

Accepted after revision: July 142004
The prevalence of asthma has increased dramatically since the 1980s. In the USA, during the period 1980-1996, the prevalence of self-reported asthma increased by $75 \%$ overall and $74 \%$ among children aged 5-14 yrs [1]. In 2001, the prevalence of physician-diagnosed asthma among children (0-17 yrs) and adults ( $\geqslant 18$ yrs) was $8.7 \%$ and $6.9 \%$, respectively [2].

The mounting problem of asthma in developed countries worldwide has sparked a variety of clinical and epidemiological research regarding the aetiology and exacerbation of the disease. One focus of recent aetiological research has been the effect of environmental factors on the development and behaviour of the immune system in children. These studies have examined the "hygiene hypothesis" of immunological development, which, in its simplest form, asserts that the developing immune system must be confronted with microbial material in order to function appropriately. Otherwise, the immune system "turns on" mechanisms that create an over-reaction to exposures, resulting in allergy and asthma. Support for the hygiene hypothesis has been found in European, Australian, New Zealand and Canadian studies of farm children, who appear to have asthma less frequently than children who have not grown up on farms [3-10]. The specific farm exposures responsible for this apparent protective effect have not been identified, but it is thought that exposure to endotoxin from livestock and poultry may be a contributing factor in the reduced asthma prevalence among farm children.

An ecological study was conducted using existing data to examine the overall relationship between asthma prevalence and farming exposures in North Carolina, USA. The study sought to determine whether there might be a basis for further research to evaluate the relationship of farming and asthma in North Carolina, where there are a variety of farm types and sizes.

\section{Subjects and methods}

Estimates of asthma prevalence among 7 th and 8th grade children (aged 12-14 yrs) were obtained from the North Carolina School Asthma Survey (NCSAS), 1999-2000, designed and conducted by the North Carolina Dept of Health and Human Services and the University of North Carolina School of Public Health, NC, USA [11]. The survey was adapted from the International Survey of Asthma and Allergies in Childhood (ISAAC) written and video questionnaires, and assessed current symptoms of wheezing and cough, as well as self-reported, physician-diagnosed asthma [12]. Responses to these items estimated the prevalence of physician-diagnosed asthma and wheezing with and without physician diagnosis.

The survey response rate was $66.8 \%$ (128,568 out of 192,248 ) for 7 th and 8th grade children enrolled in public school during 1999-2000. Response rates by school were $88 \%$ (499 out of 565) and 99 out of 100 counties. One county had unusable data due to a broken video tape, leaving the data from 98 out of 100 counties for analyses. Demographic 
information obtained from the statistical branch of the North Carolina Dept of Public Instruction was used to compare participants with nonparticipants. There were no significant differences in socioeconomic status (enrolment in the free school lunch programme), race, or sex among children who participated and those who did not [12].

County-specific data about agriculture, including numbers of livestock and poultry, and acres of crops, were obtained from the Agricultural Statistics Division of the North Carolina Dept of Agriculture and Consumer Services [13]. Statistics on cattle were reported from January 1, 2002, and statistics on hogs, pig, poultry, and crops were reported from December 1, 2001. Counties did not report livestock or poultry if their numbers did not meet the minimum for census; these included $<1,000$ hogs or pigs, $<200$ beef or milk cattle and $<500,000$ broilers (chickens raised for meat). Counties did not report crops if they did not harvest $>200$ acres.

Data regarding the number of farms and total acreage of each county were obtained from the 1997 Census of Agriculture [13]. These statistics are compiled and published by the U.S. Dept of Commerce every 5 yrs. Population estimates and descriptions of county populations were obtained from the U.S. Census Bureau [14].

\section{Statistical analysis}

Binomial regression was used to quantify the relationships between county agricultural characteristics and county prevalence of asthma and undiagnosed wheeze among 7th and 8th grade children who participated in the NCSAS. Variables for farming, such as the numbers of livestock and acres of crops, were scaled using interquartile ranges (IQR) to facilitate comparison of the regression coefficients given the diverse units and ranges of these agricultural indicators. Regression coefficients were reported as the percentage change in prevalence for each scaled unit of exposure. All models were weighted by the number of children participating in the asthma survey in each county and adjusted for the percentage of male and African-American participants, the percentage whose parents smoked and the percentage enrolled in free school lunch programmes (an indicator of socioeconomic status).

\section{Results}

The mean, median, range and IQR of county-specific asthma prevalence and farm exposures are shown in table 1.

The number of farms, acreage of hay and numbers of beef and milk cattle were all associated with modest but statistically significant decreases in asthma prevalence (table 2). The largest decreases in asthma prevalence were associated with increasing numbers of beef cattle $(-7.76 \%$ per IQR increment), acres of hay (-7.24\% per IQR increment) and numbers of farms $(-5.02 \%$ per IQR increment). Smaller, but still statistically significant, negative associations were observed for dairy cattle and broilers, whereas the associations with hogs and pigs and acres of wheat were negligible (table 2).

A similar pattern of results was observed for wheezing without a diagnosis of asthma (table 3), although the associations were generally weaker. The results were unchanged when counties with the lowest prevalence $(4 \%)$ and with $<50$ participants $(n=2)$ were excluded from the analysis. Omitting the adjustments for parental smoking, socioeconomic status, race and sex did not materially change the estimates, nor did the use of alternative indicators of socioeconomic status, including county mean income and education.

Table 1.-Mean, median, range and IQR of selected characteristics of 100 counties in North Carolina, USA

\begin{tabular}{lccc}
\hline & Mean & Median & Range \\
\hline Asthma \% $\%$ IQR & & $4.0-18.7$ \\
Undiagnosed wheeze $^{+} \%$ & 10.1 & 9.9 & $0-32.5$ \\
Total population n & 17.4 & 17.1 & $4149-695434$ \\
Survey participants $n$ & 80493 & 47879 & $8-10010$ \\
Parental smoking \% & 1253 & 793 & $0-28.5$ \\
Participants in poverty \% & 16.9 & 17.2 & $0-96.9$ \\
African-American participants \% & 38.2 & 34.2 & $0-81.5$ \\
Males \% & 34 & 33.4 & $42-62.5$ \\
Total area of county acres & 49.8 & 49.5 & $110490-607296$ \\
Farm area of county acres & 311796 & $4961-285116$ \\
Number of farms & 91223 & 800968 & $9-1366$ \\
Hay harvested acres & 494 & 415 & $0-31800$ \\
Wheat harvested acres & 7098 & 5000 & $0-44000$ \\
Beef cattle & 6749 & 3800 & $0-17500$ \\
Milk cattle & 4322 & 3100 & $0-11700$ \\
Pigs and hogs & 613 & 0 & $0-2150000$ \\
Broilers & 97892 & 4300 & $0-87800000$ \\
\hline
\end{tabular}

IQR: interquartile range (75th percentile -25 th percentile). ${ }^{\#}$ : for indicators of exposure; ${ }^{\top}$ : self-reported physician diagnosis of asthma; ${ }^{+}$: wheezing reported on the International Survey of Asthma and Allergies in Childhood (ISAAC) questionnaire without physician diagnosis of asthma.

This study suggests that certain farm exposures may be associated with lower frequency of asthma in school children. County-specific ecological measures were used to examine the relationship between asthma prevalence in school children and farm exposures in North Carolina, and it was found that statistically significant decreases in asthma prevalence were associated with hay acreage, number of farms, and numbers of beef and dairy cattle. The prevalence of asthma was not significantly associated with wheat acreage or the numbers of pigs and hogs.

These ecological findings are consistent with the hypothesis that some exposures related to farming are protective against childhood asthma. Hypotheses that farming might have protective effects focus on conditions that result in a richer microbial environment, including larger families, exposure to livestock (particularly cattle), and exposure to higher levels of 
Table 2.-Percentage change in county prevalence of physician-diagnosed asthma in 7th and 8th grade school children in relation to indicators of potential exposure to farming ${ }^{\#}$

\begin{tabular}{lcc}
\hline Exposure indicator & $\%$ change & 95\% confidence interval \\
\hline Number of farms & -5.02 & $-7.60--2.44$ \\
Dairy cattle & -0.98 & $-1.71--0.25$ \\
Beef cattle & -7.76 & $-10.31--5.20$ \\
Hogs and pigs & -0.01 & $-0.39-0.38$ \\
Broilers & -1.57 & $-2.29--0.85$ \\
Acres of hay & -7.24 & $-10.02--4.46$ \\
Acres of wheat & -0.58 & $-2.09-0.94$ \\
\hline
\end{tabular}

\#: results obtained from binomial regression models weighted by the number of participants in each county; ${ }^{\prime}$ : percentage change in prevalence for a change equivalent to one interquartile range for each exposure indicator (see table 1) estimated from separate models and adjusted for prevalence of parental smoking, socioeconomic status, sex and race among participating children.

Table 3.-Percentage change in county prevalence of undiagnosed wheezing in 7th and 8th grade school children in relation to indicators of potential exposure to farming ${ }^{\#}$

\begin{tabular}{lcc}
\hline Exposure indicator & \% change & 95\% confidence interval \\
\hline Number of farms & -5.37 & $-7.23--3.51$ \\
Dairy cattle & -0.75 & $-1.27--0.23$ \\
Beef cattle & -3.65 & $-5.47--1.83$ \\
Hogs and pigs & 0.10 & $-0.17-0.37$ \\
Broilers & -0.60 & $-1.09--0.10$ \\
Acres of hay & -2.93 & $-4.91--0.95$ \\
Acres of wheat & -0.93 & $-2.02-0.17$ \\
\hline
\end{tabular}

\#: results obtained from binomial regression models weighted by the

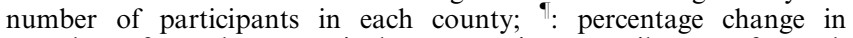
prevalence for a change equivalent to one interquartile range for each exposure indicator (see table 1) estimated from separate models and adjusted for prevalence of parental smoking, socioeconomic status, sex and race among participating children.

endotoxin, a cell wall component of Gram-negative bacteria [15].

The focus has turned to endotoxin as a protective factor because of its potential to suppress the innate immune responses involved in immunoglobulin E-mediated allergy [15]. Endotoxin is ubiquitous in the environment, but levels tend to be high in environments where there are farm animals, such as cows, horses, and pigs [3, 16], and during wheat harvest [17].

As in any ecological study, the finding of an association at the population level does not necessarily imply that the same relationship exists among individuals. Individual-level confounding is particularly difficult to control and may have affected the results, despite adjustments for ecological indicators of smoking, ethnicity and socioeconomic level. Interpretation of the findings for hogs and pigs was complicated by the observation that intensive hog operations are concentrated in areas with high proportions of poor, nonWhite residents [18]. Therefore, race and poverty may be causes of exposure, as well as potential confounders.

Despite the well-known limitations of ecological studies, this study is, nevertheless, useful as a cost-effective initial examination of the overall relationship between asthma and exposures to farming in the USA [19]. The few studies examining these relationships in the USA have resulted in equivocal findings. One study measured asthma prevalence in two counties in Iowa, where the predominant land use is farming [20]. The potential protective effect of farming was observed in only one of the study counties, and asthma prevalence was similar to that found in large mid-western cities. The authors suggested that there might be little difference in environmental exposures between farm and non-farm residents, since agricultural exposures are ubiquitous in Iowa. A case-control study nested within the Children's Health Study in southern California examined the relationships between asthma and a variety of environmental exposures, and found that children who had ever been exposed to farm animals or crops and crop dust had an increased risk of asthma compared with children who had never had those exposures [21].

The current findings of associations between reduced asthma prevalence among adolescents and indicators of exposure to farming in North Carolina, USA, provide a stimulus for further study with measurement of exposure at the individual level to investigate exposures that may be protective against the development of asthma.

\section{References}

1. Centers for Disease Control and Prevention. Asthma's impact on children and adolescents. Atlanta, Air Pollution and Respiratory Health Branch, 2002.

2. Centers for Disease Control and Prevention. Asthma prevalence, health care use and mortality, 2000-2001. Atlanta, National Center for Health Statistics, 2003.

3. Braun-Fahrlander C, Riedler J, Herz U, et al. Environmental exposure to endotoxin and its relation to asthma in schoolage children. $N$ Engl J Med 2002; 347: 869-877.

4. Downs SH, Marks GB, Mitakakis TZ, Leuppi JD, Car NG, Peat JK. Having lived on a farm and protection against allergic diseases in Australia. Clin Exp Allergy 2001; 31: 570-575.

5. Ernst P, Cormier E. Relative scarcity of asthma and atopy among rural adolescents raised on a farm. Am J Respir Crit Care Med 2000; 161: 1563-1566.

6. Klintberg B, Berglund N, Lilja G, Wickman M, van HageHamsten M. Fewer allergic respiratory disorders among farmers' children in a closed birth cohort from Sweden. Eur Respir J 2001; 17: 1151-1157.

7. Leynaert B, Neukirch C, Jarvis D, Chinn S, Burney P, Neukirch F. Does living on a farm during childhood protect against asthma, allergic rhinitis, and atopy in adulthood? Am J Respir Crit Care Med 2001; 164: 1829-1834.

8. Riedler J, Eder W, Oberfeld G, Schreuer M. Austrian children living on a farm have less hay fever, asthma, and allergic sensitization. Clin Exp Allergy 2000; 30: 194 200.

9. Riedler J, Braun-Fahrlander C, Eder W, et al. Exposure to farming in early life and development of asthma and allergy: a cross-sectional survey. Lancet 2001; 358: 1129-1133.

10. Wickens K, Lane JM, Fitzharris P, et al. Farm residence and exposures and the risk of allergic diseases in New Zealand children. Allergy 2002; 57: 1171-1179.

11. North Carolina School Asthma Survey, 2001. Raleigh, N.C. Dept of Health and Human Services, 2001.

12. Yeatts K, Davis K, Sotir M, Herget C, Shy C. Who gets diagnosed with asthma? Frequent wheeze among adolescents with and without a diagnosis of asthma. Pediatrics 2003; 111 : $1046-1054$.

13. N.C. Dept of Agriculture and Consumer Services. Ag Statistics. Raleigh, Agricultural Statistics Division, 2003.

14. United States Census 2000. Washington DC, United States Census Bureau, 2000.

15. Strachan DP. Family size, infection and atopy: the first decade of the "hygiene hypothesis". Thorax 2000; 55: Suppl. 1, S2-S10. 
16. Gereda J. Levels of environmental endotoxin and prevalence of atopic disease. JAMA 2000; 284: 1652-1653.

17. Viet SM. Acute respiratory effects and endotoxin exposure during wheat harvest in Northeastern Colorado. Appl Occup Environ Hyg 2001; 16: 685-697.

18. Wing S, Wolf S. Intensive livestock operations, health, and quality of life among East North Carolina residents. Environ Health Perspect 2000; 108: 233-238.

19. Morgenstern H. Ecological studies. In: Rothman K,
Greenland S, eds. Modern epidemiology. 2nd Edn. Philadelphia, Lippincott-Raven, 1998; pp. 459-480.

20. Chrischilles E, Ahrens R, Kuehl A, et al. Asthma prevalence and morbidity among rural Iowa schoolchildren. J Allergy Clin Immunol 2004; 113: 66-71.

21. Salam MT, Li Y, Langholz B, Gilliland FD. Early-life environmental risk factors for asthma: findings from the Children's Health Study. Environ Health Perspect 2004; 112: 760-765. 